\title{
ANTIOXIDANT ACTIVITY IN LEAVES OF SESBANIA GRANDIFLORA (L.) PERS.
}

\author{
PRADEESH $\mathbf{S}^{1}$, SWAPNA T $\mathbf{S}^{2 *}$ \\ ${ }^{1}$ Department of Botany, Christian College, Thiruvananthapuram - 695 572, Kerala, India. ${ }^{2}$ Department of Botany, University of Kerala, \\ Thiruvananthapuram - 695 581, Kerala, India. Email: swapnats@yahoo.com
}

Received: 01 June 2015, Revised and Accepted: 01 October 2017

ABSTRACT

Objective: The main aim of this study was to evaluate the antioxidants present in Sesbania grandiflora (L.) Pers. belongs to the family Fabaceae.

Methods: Fresh samples were used for the analysis of antioxidants such as total phenol, carotenoids, Vitamin-A, Vitamin-C, Vitamin-E, peroxidase (POD), catalase (CAT), superoxide dismutase (SOD), ascorbate peroxidase, monodehydroascorbate reductase, and glutathione reductase by standard estimation methods.

Results: Present studies revealed that this wild leafy plant has numerous antioxidant factors that destroying the free radicals that damage the cells.

Conclusion: S. grandiflora contain many enzymatic and non-enzymatic antioxidants and could be a good source of dietary antioxidants which play an important role in the prevention of diseases associated with oxidative stress.

Keywords: Total phenol, Vitamin C, Vitamin E, Peroxidase, Superoxide dismutase, Ascorbate peroxidase, Catalase, Monodehydroascorbate reductase, Glutathione reductase.

(C) 2018 The Authors. Published by Innovare Academic Sciences Pvt Ltd. This is an open access article under the CC BY license (http://creativecommons. org/licenses/by/4. 0/) DOI: http://dx.doi.org/10.22159/ajpcr.2018.v11i1.7132

\section{INTRODUCTION}

The protective action of vegetables has been attributed to the presence of antioxidants, especially antioxidant vitamins including ascorbic acid, $\alpha$-tocopherol, and $\beta$-carotene [1]. However, numerous studies have conclusively shown that the majority of the antioxidant activity may be from compounds such as flavonoids, isoflavone, flavones, anthocyanin, catechin and isocatechin rather than from Vitamin C, E, and $\beta$-carotene [2]. The consumption of food and beverages rich in phenolics contents can reduce the risk of heart disease by slowing the progression of arteriosclerosis by acting as antioxidants toward low-density lipoproteins [3]. The antioxidant activity of phenolics is mainly because of their redox properties, which allow them to act as reducing agents, hydrogen donors, singlet oxygen quenchers, and metal chelators [4]. A large number of plant sources including many vegetables and fruits have been reported to have high antioxidant activities, for example, mushrooms, cabbage, cauliflowers, garlic, broccoli, pinto beans, beans, beet, and corn. Other vegetables such as kale, spinach, brussel sprouts, alfalfas sprouts, red bell pepper, onion, eggplants, and cucumber are also rich sources of antioxidants [5].

In traditional societies, nutrition and health care are strongly interconnected, and many plants have been consumed both as food and for medicinal purposes [6]. Free radicals are highly reactive compounds. They are chemical species associated with an odd or unpaired electron and can be formed when oxygen interacts with certain molecules. They are neutral, short-lived, unstable and highly reactive to pair with the odd electron and finally achieve a stable configuration. Once formed these highly reactive radicals can initiate a chain reaction they are capable of attacking the healthy cells of the body, causing them to lose their structure and function. Cells may function poorly or die if this occurs [7]. Antioxidant is a molecule capable of slowing or preventing the oxidation of other molecules and thereby reduces the possibility of cancer and other diseases. The major action of antioxidants in cells is to prevent damage due to the action of reactive oxygen species (ROS). Studies have indicated that antioxidant supplements have benefits for health. All living organisms contain complex systems of antioxidant enzymes and chemicals, some to combat oxidative damage to cellular components and others to regulate and sustain natural cellular processes such as oxidative phosphorylation and the formation of disulfide bonds [8].

Oxidative stress has been implicated in a variety of diseases such as cardiovascular diseases and cancer [9]. ROS, which induces the oxidative stress, are produced by the reaction of oxygen with radiation, various environmental chemicals, or produced in the course of metabolism by one-electron transfers to an unstable oxygen molecule. ROS respond to most of the biological molecules and damage membranes, enzymes and genes [10]. Since the generation of ROS cannot control, antioxidants and radical scavengers are important to suppress the oxidative stress [11]. Many herbal diets contain antioxidative components such as phenolics, terpenoids, and tocopherols [1]. The production of ROS, such as singlet oxygen $\left({ }^{1} \mathrm{O}_{2}\right)$, superoxide radical $\left(\mathrm{O}_{2}^{-}\right)$, and hydrogen peroxide $\left(\mathrm{H}_{2} \mathrm{O}_{2}\right)$, intrinsically accompanies photosynthesis [12]. Hydrogen peroxide $\left(\mathrm{H}_{2} \mathrm{O}_{2}\right)$ is generated by the glycolate oxidase reaction in the process of photorespiration [13]. Thus, the consumption of fruits and vegetables could reduce the risk of chronic diseases.

Therefore, in the present investigation, an attempt has been made to understand the antioxidant properties of the wild leafy edible plant Sesbania grandiflora, which possess numerous medicinal properties and are consumed by the common peoples of Kerala in India. Studies on the antioxidant value of wild plants are of considerable significance since it may help to identify forgotten medicinal resources.

\section{MATERIALS AND METHODS}

Plant material collection and sample preparation $S$. grandiflora were collected from different localities of Thiruvananthapuram district of Kerala state in India. Fresh samples were used for the antioxidant analysis and experiments were repeated thrice to confirm the result. 


\section{Antioxidant analysis}

The analysis was performed following standard methods for estimation of different non-enzymatic and enzymatic antioxidants such as total phenol, carotenoids, Vitamin-A, Vitamin-C, Vitamin-E, peroxidase (POD: EC 1.11.1.7), catalase (CAT: EC 1.11.1.6), superoxide dismutase (SOD) (SOD: EC 1.15.1.1), ascorbate peroxidase (APX) (APX: EC 1.11.1.11), monodehydroascorbate reductase (MDHAR) (MDHAR: EC 1.6.5.4), and glutathione reductase (GR) (GR: EC 1.6.4.2).

\section{Non-enzymatic antioxidants}

For the estimation of total phenol fresh samples were refluxed in boiling $80 \%$ methanol for 20 minutes. Total phenol present in the sample was estimated by the Folin-Ciocalteu method and read the absorbency at $650 \mathrm{~nm}$ against a blank [14]. Carotenoids by the method of Arnon [15], $\beta$-carotene (Vitamin A) was determined following the method of IUPAC 1987 [16], Vitamin C present in the sample by the method of Sadasivam and Balasubramanian [17] and Vitamin E by the method of Rosenberg [18].

\section{Enzymatic antioxidants}

Estimation of enzymatic antioxidants like peroxidase by Putter method [19], catalase by the method (extinction coefficient of $39.4 \mathrm{mM}^{-1} \mathrm{~cm}^{-1}$ ) of Cakmak et al., [20], superoxide dismutase by nitro-blue tetrazolium method [21], APX by Nakano and Asada [22] method (extinction coefficient of $2.8 \mathrm{mM}^{-1} \mathrm{~cm}^{-1}$ ), MDHAR by Miyake and Asada (extinction coefficient of $6.2 \mathrm{mM}^{-1} \mathrm{~cm}^{-1}$ ) method [23], and GR by the method (extinction coefficient of $6.2 \mathrm{mM}^{-1} \mathrm{~cm}^{-1}$ ) of Foyer and Halliwell [24].

\section{Statistical analysis}

All experimental results were statistically analyzed and expressed as a mean \pm standard deviation.

\section{RESULTS}

\section{Non-enzymatic antioxidants}

The total phenol content in leaves of $S$. grandiflora was studied, and a higher concentration of phenols was found $\left(0.356 \mathrm{mg} \mathrm{g}^{-1}\right)$ as shown in Fig. 1, compared to reported wild green leafy vegetables such as Solanum macrocarpon belongs to the family Solanaceae and Amaranthus cruentus belongs to the family Amaranthaceae [25]. High content of carotenoids was present in leaves $\left(0.456 \mathrm{mg} \mathrm{g}^{-1}\right)$ of $S$. grandiflora (Fig. 1) compared to other green leafy vegetables reported such as Centella asiatica, Murraya koenigii, Trigonella foenum, and Amaranthus species [26].

The results showed that the leaves of Sesbania have a higher amount of Vitamin A (0.902 $\left.\mathrm{mg} \mathrm{g}^{-1}\right)$ as showed in Fig. 1. This amount was higher compared to $C$. asiatica of Apiaceae, which was reported as a green leafy vegetable in India [26]. High amount of Vitamin C was present in leaves of Sesbania ( $\left.0.874 \mathrm{mg} \mathrm{g}^{-1}\right)$ as presented in Fig. 1, compared to other reported green leafy vegetable like $T$. foenum belongs to the family Papilionaceae [26]. Analysis of S. grandiflora also showed a high amount of Vitamin E (Fig. 1) in leaves $\left(0.893 \mathrm{mg} \mathrm{g}^{-1}\right)$, compared to C. asiatica of Apiaceae, which was reported as a green leafy vegetable of India [26].

\section{Enzymatic antioxidants}

This study showed that $S$. grandiflora has a higher concentration of peroxidase in leaves (47.546 $\mu \mathrm{m} / \mu \mathrm{g}$ protein) as showed in Fig. 2 and compared to leafy vegetables reported such as Amaranthus spinosus, Spergula arvensis, and Spinacia oleracea of families such as Amaranthaceae, Caryophyllaceae, and Chenopodiaceae, respectively [27]. The $S$. grandiflora has a higher concentration of catalase (Fig. 2) in leaves (19.901 $\mu \mathrm{m} / \mu \mathrm{g}$ protein) compared to other leafy vegetables reported such as A. spinosus, S. arvensis, and Spinacia oleracea of families such as Amaranthaceae, Caryophyllaceae, and Chenopodiaceae [27]. The result showed that very higher amount of SOD was found (Fig. 2) in the plant part such as S. grandiflora leaves (15.727 $\mu \mathrm{m} / \mu \mathrm{g}$ protein) compared to other leafy vegetables reported such as A. spinosus, S. arvensis, and Spinacia oleracea [27]. Analysis also showed that high amount of MDHAR, GR and APX were present in Sesbania leaves (Fig. 3). Among the different antioxidant enzymes MDHAR, GR, APX, and catalase were present in higher amount in S. grandiflora leaves (GR 240.374, MDHAR 206.394, and APX 334.401, CAT $19.901 \mu \mathrm{m} / \mu \mathrm{g}$ protein) compared to common leafy vegetables reported like Glycine max of Papilionaceae [28].

\section{DISCUSSION}

\section{Non-enzymatic antioxidants}

Oxidative stress can lead to inhibition of photosynthesis, respiration processes and thus plant growth. Plants have evolved enzymatic and non-enzymatic systems to scavenge active oxygen species. Phenolic compounds can protect the human body from free radicals, whose formation is associated with the inherent aerobic metabolism of cells. The antiradical activity of flavonoids and phenols is principally based on the structural relationship between different parts of their chemical

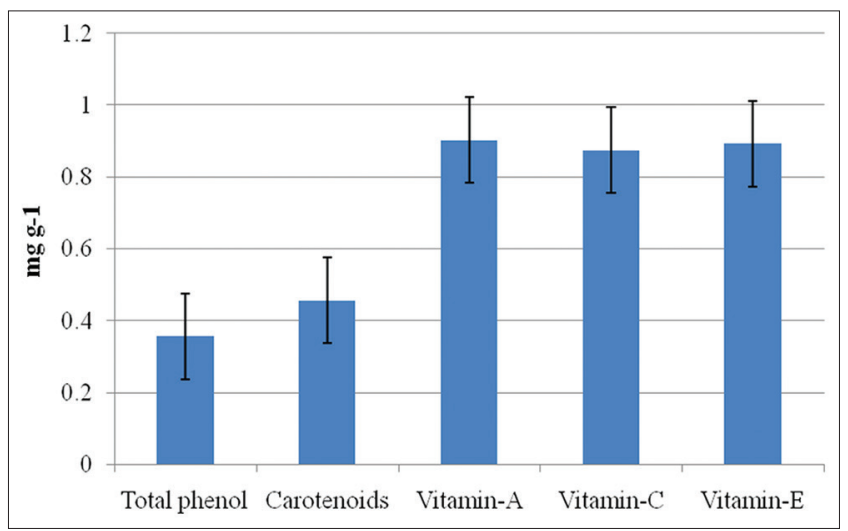

Fig. 1: Non-enzymatic antioxidants in Sesbania grandiflora leaves

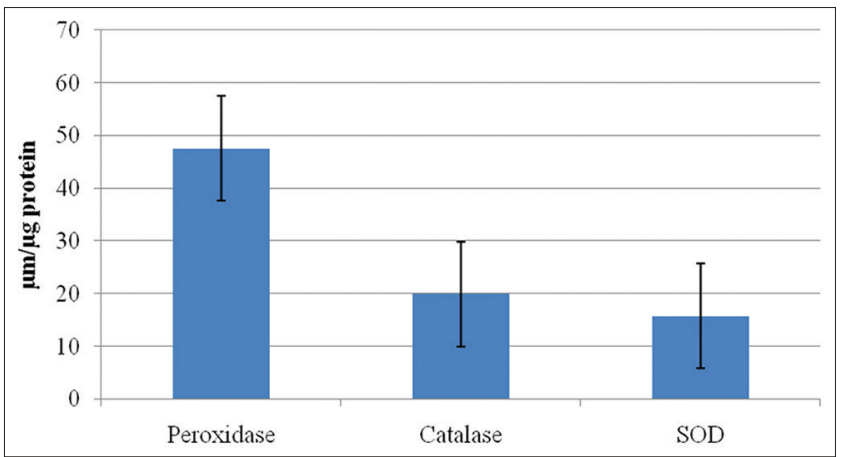

Fig. 2: Peroxidase, catalase, and superoxide dismutase in Sesbania grandiflora leaves

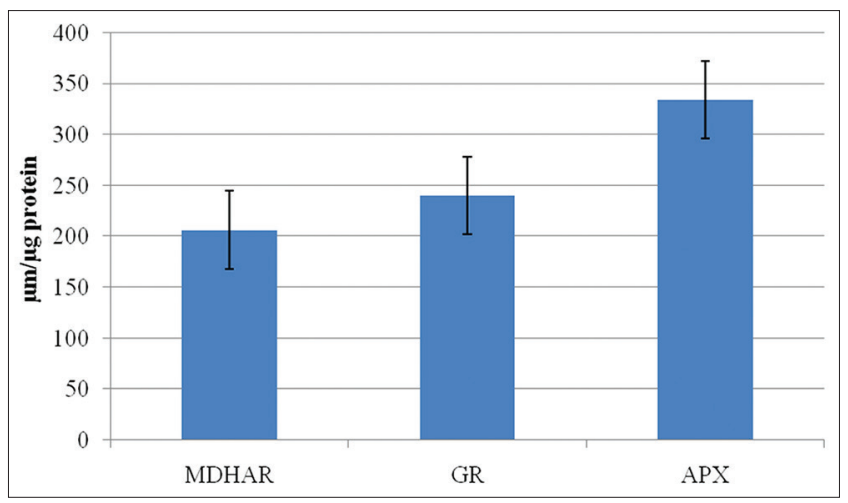

Fig. 3: Monodehydroascorbate reductase, glutathione reductase, and ascorbate peroxidase in Sesbania grandiflora leaves 
structure [29]. Plant phenolics have the potential to function as antioxidants by trapping free radicals generated in oxidative chemistry which then normally undergoes coupling reactions leading eventually to color polymeric or oligomeric products [30]. Carotenes occurring in different chemical forms have protected photosystems by various ways, and their levels are altered during physiological and pathological conditions [31].

Vitamin-A ( $\beta$-carotene) is a fat-soluble vitamin supplied to the body in the form of its precursor, $\beta$-carotene, which is present in fruits, vegetables, leafy greens, etc., and it is not stored in the body when consumed abundant [16]. Vitamin C is found in fruits, particularly fruits and juices and green leafy vegetables [32] which are a water-soluble antioxidant with a unique capacity to "scavenge" aqueous peroxyl radicals before damaging the lipids [33]. Vitamin $\mathrm{E}$ is one of the fatsoluble vitamins present in plant tissues and is considered to be the most active form of $\alpha$-tocopherol [29]. It is an effective quenching agent for both singlet oxygen and alkyl peroxides, and vitamin $\mathrm{E}$ biosynthetic capacity is reported to be increased in response to the demands of oxidative stress [34-36]. S. grandiflora has a significant amount of nonenzymatic antioxidants for protecting body against the action of free radicals.

\section{Enzymatic antioxidants}

The enzymatic defense against the ROS is essential for plants under biotic or abiotic stress $[37,38]$. The antioxidative enzymes, peroxidase (POD), catalase (CAT), SOD, APX, and GR, and other ascorbateglutathione cycle enzymes MDHAR and DHAR catalyze the synthesis, degradation, and recycling of antioxidant molecules and can directly catalyze the removal of free radicals from the cells. Peroxidase (POD) includes in its widest sense a group of specific enzymes such as NAD-peroxidase, NADP-peroxidase, and fatty acid peroxidase as well as a group of very non-specific enzymes from different sources which are simply known as POD. POD catalyzes the dehydrogenation of a large number of organic compounds such as phenols, aromatic amines, and hydroquinones. POD is present in animals, higher plants and other organisms and the best-studied one is horseradish POD [19].

Catalase is a heme-containing enzyme that catalyzes the dismutation of hydrogen peroxide into water and oxygen. The enzyme is noted in all aerobic eukaryotes and is important in the removal of $\mathrm{H}_{2} \mathrm{O}_{2}$ generated in peroxisomes (microbodies) by oxidases involved in $\beta$-oxidation of fatty acids, the glyoxylate cycle (photorespiration), and purine catabolism [34]. Detoxification of hydrogen peroxide is mediated by catalase; which is mostly localized in peroxisomes. However, catalase possesses a very low affinity for $\mathrm{H}_{2} \mathrm{O}_{2}$ and its activity is either extremely low or not-detectable in the cytosol, mitochondria and chloroplast [39].

APX is the first enzyme that catalyzes the reduction of $\mathrm{H}_{2} \mathrm{O}_{2}$ to water and has high specificity and affinity for ascorbate as reductant [40]. Superoxide dismutase, originally found by McCord and Fridovich [41], catalyzes the dismutation of superoxide to hydrogen peroxide and oxygen. High specificity APX is the first enzyme of photorespiration and catalyzes the reduction of $\mathrm{H}_{2} \mathrm{O}_{2}$ to water and has an affinity for ascorbate as reductant [41]. GR is the rate-limiting enzyme in $\mathrm{H}_{2} \mathrm{O}_{2}$ scavenging pathway, and it is involved in the maintenance of a high ratio of reduced and oxidised glutathione, which is required for the regeneration of ascorbate [42]. Presence of these enzymatic and nonenzymatic antioxidants in $S$. grandiflora helps in protecting the body from free radicals.

\section{CONCLUSION}

Many natural plant products have a variety of biological activities and have always been a significant source of new lead compounds in pharmaceutical industries. Foods from plant origin usually contain natural antioxidants that can scavenge free radicals; these different phytochemicals have a protective effect against diseases. The most likely and practical way to fight against degenerative diseases is to improve body antioxidant status, which could be achieved by higher consumption of vegetables and fruits. Leafy vegetables contain numerous phytochemicals in addition to phenolic compounds; however, the various conventional food processing techniques could affect the antioxidant phytochemicals and their activity. All cells contain complex systems of antioxidants to prevent chemical damage to the cell components by oxidation. Antioxidants are totally critical for maintaining optimal cellular and systemic health and well-being. Naturally, there is a dynamic balance between the amount of free radicals produced in the body and antioxidants to scavenge or quench them to protect the body against the deleterious effects $[43,44]$. The amount of antioxidant principles present under normal physiological conditions may be insufficient to neutralize free radicals generated. Therefore, it is obvious to enrich our diet with antioxidants to guard against harmful diseases. Hence, there has been an increased interest in the food industry and in, preventive medicine in the development of "Natural antioxidants" from plant materials [5]. S. grandiflora contain many enzymatic and non-enzymatic antioxidants and could be a good source of dietary antioxidants which play an important role in the prevention of diseases associated with oxidative stress.

\section{REFERENCES}

1. Cao G, Stfie E, Prior RL. Antioxidant capacity of tea and common vegetables. Agric Food Chem 1996;44:3425-31

2. Chu YF, Sun J, WuX, Liu RH.Antioxidant and anti-proliferative activities of common vegetables. J Agric Food Chem 2002;50(23):6910-6.

3. Alia M, Horcajo C, Bravo L, Goya L. Effect of grape antioxidant dietary fiber on the total antioxidant capacity and the activity of liver antioxidant enzymes in rats. Nutr Res 2003;23:1251-67.

4. Frei B, Ames BN. In: Scandalios JG, editor. The Molecular Biology of Free Radical Scavenging Systems. $1^{\text {st }}$ ed. New York: Cold Spring Harbor Laboratory Press; 1992. p. 23-45.

5. Yang J, Lin H, Mau J. Antioxidant properties of several commercial mushrooms. Food Chem 2002;77:229-35

6. Pieroni A. Medicinal plants and food medicines in the folk traditions of the upper Lucca Province, Italy. J Ethnopharmacol 2000;70(3):235-73.

7. Ames BN, Shigenaga MK, Hagen TM. Oxidants, antioxidants, and the degenerative diseases of aging. Proc Natl Acad Sci U S A 1993;90(17):7915-22.

8. Wang JY, Wen LL, Huang YN, Chen YT, Ku MC. Dual effects of antioxidants in neurodegeneration: Direct neuroprotection against oxidative stress and indirect protection via suppression of glia-mediated inflammation. Curr Pharm Des 2006;12(27):3521-33.

9. Ferguson LR. Antimutagens as cancer chemopreventive agents in the diet. Mutat Res 1994;307(1):395-410.

10. Jimenez M, Garcia-Carmona F. Myricetin, an antioxidant flavonol, is a substrate of polyphenol oxidase. Sci Food Agric 1999;79:1993-2000.

11. Chaudière J, Ferrari-Iliou R. Intracellular antioxidants: From chemical to biochemical mechanisms. Food Chem Toxicol 1999;37(9-10):949-62.

12. Mano J, Torii Y, Hayashi S, Takimoto K, Matsui K, Nakamura K, et al. The NADPH: Quinone oxidoreductase P1-zeta-crystallin in Arabidopsis catalyzes the alpha, beta-hydrogenation of 2-alkenals: Detoxication of the lipid peroxide-derived reactive aldehydes. Plant Cell Physiol 2002;43(12):1445-55.

13. Foyer $\mathrm{CH}$, Descourvieres P, Kunert KJ. Protection against oxygen radicals: An important defence mechanism studied in transgenic plants. Plant Cell Environ 1994;17:507-23.

14. Mayr U, Treutter D, Santos-Buelga C, Bauer H, Feucht W. Developmental changes in the phenol concentrations of 'golden delicious' apple fruits and leaves. Phytochemistry 1995;38(5):1151-5.

15. Witham FH, Blaydes DF, Devlin RM. Experiments in Plant Physiology. New York: Van Nostrand; 1971. p. 245.

16. Bayfield RF, Cole ER. Colorimetric estimation of vitamin A with trichloroacetic acid. Methods Enzymol 1980;67:189-95.

17. Sadasivam S, Balasubramanian T. Practical Manual in Biochemistry. Coimbatore: Tamil Nadu Agricultural University; 1987. p. 14.

18. Rosenberg HR. Chemistry and Physiology of Vitamins. New York: Inter Science Publishers Inc.; 1992. p. 452-3.

19. Putter J. In: Bergmeyer HU, editor. Methods of Enzymatic Analysis. $2^{\text {nd }}$ ed. New York: Academic Press; 1974. p. 685

20. Cakmak I, Strbac D, Marschner H. Activities of hydrogen peroxide scavenging enzymes in germinated wheat seeds. Exp Bot 1993;44:127-32

21. Gong H, Zhu X, Chen K, Wang S, Zhang C. Silicon alleviates oxidative damage of wheat plants in pots under drought. Plant Sci 
2005;169:313-21.

22. Nakano Y, Asada K. Hydrogen peroxide is scavenged by ascorbatespecific peroxidase in spinach chloroplasts. Plant Cell Physiol 1981;22:867-80.

23. Miyake C, Asada K. Thylakoid-bound APX in spinach chloroplasts and photoreduction of its primary oxidation product monodehydroascorbate radicals in thylakoids. Plant Cell Physiol 1992;33:541-53.

24. Foyer $\mathrm{CH}$, Halliwell $\mathrm{B}$. The presence of glutathione and glutathione reductase in chloroplasts: A proposed role in ascorbic acid metabolism. Planta 1976;133(1):21-5.

25. Oboh G, Akindahunsi AA. Change in the ascorbic acid, total phenol and antioxidant activity of sun-dried commonly consumed green leafy vegetables in Nigeria. Nutr Health 2004;18:29-36.

26. Gupta S, Prakash J. Studies on Indian green leafy vegetables of their antioxidant activity. Plant Foods Hum Nutr 2008;64:39-45.

27. Smitha KR, Sudha G. Antioxidant activity of Spergula arvensis, Amaranthus spinosis and Spinacia oleracea. Int J Univ Pharm Life Sci 2011;1(3):2249-65.

28. Gillespie KM, Rogers A, Ainsworth EA. Growth at elevated ozone or elevated carbon dioxide concentration alters antioxidant capacity and response to acute oxidative stress in soybean (Glycine max). J Exp Bot 2011;62(8):2667-78.

29. Rice-Evans C, Miller NJ. Antioxidants: The case for fruit and vegetables in the diet. Br Food J 1995;97:35-40.

30. Lewis NG. Plant phenolics. In: Alscher RG, Hess JL, editors. Antioxidants in Higher Plants. Boca Raton: CRC Press; 1993. p. 136-62.

31. Rangana S. Handbook of Analysis of Quality Control for Fruits and Vegetable Product. $2^{\text {nd }}$ ed. New Delhi: Tata-McGraw-Hill Publ. Co. Ltd.; 1976. p. 1-545.

32. Block G, Patterson B, Subar A. Fruit, vegetables, and cancer prevention: A review of the epidemiological evidence. Nutr Cancer 1992;18:1-29.

33. McKersie BD. Oxidative Stress, Department of Crop Science, University of Guelph; 1996. Available from: http://www.agronomy.
psu.edu/Courses/AGROS518/Oxygen.htm\#activation. [Last accessed on 2007 Feb 08]

34. Sumita D, Maitry P, Patel N. Antioxidant activities of some less utilized edible fruits. Int J Curr Pharm Res 2017;9(5):28-31.

35. Hausladen A, Alscher RG. Glutathione. In: Alscher RG, Hess JL, editors. Antioxidants in Higher Plants. Boca Raton: CRC Press; 1993. p. 1-23.

36. Kale MA, Bindu S, Khadkikar P. Role of antioxidants and nutrition in oxidative stress: A review. Int J Appl Pharm 2015;7(1):1-4.

37. Manjunatha G, Kumar P, Chikkappaiah L, Nagayya S. Nutritional analysis of edible wild plants used by hakkipikki tribes of Hassan district, Karnataka, India. Int J Pharm Pharm Sci 2016;8(8):390-3.

38. Iwansyah AC, Damanik RM, Kustiyah I, Hanafi M. Relationship between antioxidant properties and nutritional composition of some galactopoietics herbs used in Indonesia: A comparative study. Int J Pharm Pharm Sci 2016;8(12):236-43.

39. Ratnam DV, Ankola DD, Bhardwaj V, Sahana DK, Kumar MN. Role of antioxidants in prophylaxis and therapy: A pharmaceutical perspective. J Control Release 2006;113(3):189-207.

40. McCord JM, Fridovich I. Superoxide dismutase. An enzymic function for erythrocuprein (hemocuprein). J Biol Chem 1969;244(22):6049-55.

41. Alscher RG, Hess JL. Antioxidants in Higher Plants. Boca Raton: CRC Press; 1993.

42. Sudhakar C, Lakshmi A, Giridarakumar S. Changes in the antioxidant enzyme efficacy in two high yielding genotypes of mulberry (Morus alba L.) under $\mathrm{NaCl}$ salinity. Plant Sci 2001;161:613-9.

43. Naritsara T, Pannapa P, Pattra S. Evaluation of antioxidant and antibacterial activities of fresh and freeze-dried selected fruit juices. Asian J Pharm Clin Res 2017;10(9):156-60.

44. Gyanranjan M, Sabuj S, Kunja BS. Evaluation of phytochemical constituents and antimicrobial properties of Mangifera indica L. Leaves against urinary tract infection-causing pathogens. Asian J Pharm Clin Res 2017;10(9):169-73. 